\title{
Contribuições de uma teoria da consciência irrefletida para uma filosofia da liberdade a partir de A transcendência do Ego*
}

\section{Contributions from an unreflective consciousness theory to a philosophy of freedom on La Transcendance de I'Ego}

DOI:10.12957/ek.2018.39631

Dnda. Deborah Moreira Guimarães deborahkiedis@hotmail.com Universidade Federal de São Paulo

O propósito desse artigo é explicitar os aspectos fundamentais acerca da teoria da consciência desenvolvida por Sartre em A transcendência do Ego no âmbito da passagem de seu projeto fenomenológico ao seu projeto ético. Partiremos da dicotomia entre "consciência e mundo" a fim de alcançarmos a distinção da consciência em níveis, o que será de extrema importância para se compreender o propósito ético que também envolve a interpretação da constituição egoica humana em sua relação com a condição de ser-no-mundo.

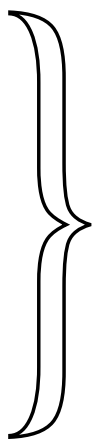

PALAVRAS-CHAVE Fenomenologia. Sartre. Consciência. Ética

We intend to explain the fundamental aspects on Sartre's theory of consciousness in his work La Transcendance de l'Ego in the context of the passage from his phenomenological to his ethical project. We start from the dichotomy between "conscience and world" in order to reach the distinction of consciousness in levels, which is extremely important to understand also the ethical purpose that involves the interpretation of the human egoic constitution in its relation to the condition of being-in-the-world.

KEY-WORDS Phenomenology. Sartre. Consciousness. Ethics 


\section{Introdução}

A obra $A$ transcendência do Ego desempenha um papel fundamental no contexto da instauração do discurso fenomenológico sartriano, apontando para seu caráter intermediário em relação à passagem do projeto fenomenológico ao projeto ético, sendo este desenvolvido com base nas teses levantadas no texto em questão.

O primeiro ponto desse estudo consiste na breve retomada do posicionamento de Sartre frente a seus principais interlocutores: os estudiosos da escola neokantiana e Edmund Husserl, responsáveis por instaurar a compreensão de fenomenologia como ciência de estudo e por disseminar suas principais teses, como o problema decorrente da dicotomia "consciência e mundo".

Em seguida, trataremos da divisão da consciência em níveis, tendo como foco a importância do cogito cartesiano na elaboração da distinção entre consciência de primeiro grau e consciência de segundo grau, o que culminará no assunto do tópico seguinte, a saber, a consciência de terceiro grau, e na análise da natureza e da constituição do Ego como fator responsável por direcionar a consciência à apreensão do Eu como objeto que se dá no mundo.

Por fim, caberá relacionar brevemente o projeto fenomenológico de Sartre à sua filosofia da liberdade, tendo como base as principais teses desenvolvidos ao longo d'A transcendência do Ego, como a afirmação de que o Ego está situado no mundo e de que o mundo é objeto da consciência, o que evidencia a passagem de um discurso fenomenológico para uma ontologia que visa apreender o fenômeno de ser apontando para o caráter ético decorrente de sua condição fundamental de existência: ser-no-mundo.

\section{0 projeto sartriano frente ao neokantismo e à fenomenologia de Husserl: o problema "consciência e mundo"}

Nosso foco é tratar de alguns aspectos da Fenomenologia no jovem Sartre, suscitada a partir da instauração da fenomenologia de Husserl e do posicionamento de Sartre frente ao projeto filosófico kantiano, mais precisamente à sua retomada com o neokantismo. É a partir deste posicionamento que surge, então, o projeto de $A$ transcendência do Ego, como já foi exposto, no qual Sartre afirma que o Ego não é um habitante da consciência, uma vez que se encontra lançado no mundo. ${ }^{1}$

1 Cf.: "Pretendemos mostrar aqui que o Ego não está nem formalmente nem materialmente na consciência: ele está lá fora, no mundo, é um ser do mundo, como o Ego do outro" (SARTRE, 2010, p. 183). 
Cabe explicitar, primeiramente, a maneira pela qual Sartre se posiciona frente à tradição neokantiana e à fenomenologia husserliana, apontando para a existência de um sentido "realista" na transcendência do Ego em relação ao elemento constitutivo existente em Kant, ultrapassando a validação do conhecimento kantiano e buscando verificar como o sentido obtém validade como tal.

A esse questionamento surge como resposta a noção de que, para a fenomenologia, no ato de apresentação da matéria empírica já ocorre o elemento normativo, não havendo distinção entre o empírico e o transcendental, o que assinala uma grande distinção entre o projeto kantiano e o projeto fenomenológico. É nesse ponto que reside também a divergência de Sartre em relação a Husserl, uma vez que este buscou reduzir o problema constitutivo para tentar identificar onde poderia ocorrer, em algum momento, uma hierarquia lógica entre o transcendental e o empírico.

Para Sartre, todavia, o transcendental e o empírico formavam uma só coisa, ou seja, aquilo que seria conhecido como um núcleo concreto. Para o existencialismo francês, do qual Sartre fazia parte, o transcendental e o empírico eram indistintos e formavam a concretude das vivências em fluxo. A noção de concretude surge enraizada na concepção de intencionalidade ${ }^{2}$, pois esta passa a ser a condição para que aquela se dê. Em outros termos, é na intencionalidade da consciência, compreendida então como a atividade realizada pela consciência enquanto consciência de algo, que se dá a concretude, formada por meio da junção/indistinção entre o campo das vivências no mundo da vida (Lebenswelt) ${ }^{3} \mathrm{e}$ as próprias condições de possibilidade de realização de tais vivências.

Com a fenomenologia de Husserl, em grande parte influenciada por seu professor Franz Brentano ${ }^{4}$, criou-se uma espécie de dualismo entre consciência e mundo, uma vez que Husserl concebia o mundo como um objeto da consciência. Havia uma relação de dependência mútua entre consciência e mundo, pois este não poderia ser concebido sem que uma consciência lhe desse sentido. As-

2 A noção de intencionalidade foi elaborada por Husserl como a atividade que a consciência realiza, trata-se de sua marca constitutiva: o fato de a consciência sempre ter que ser consciência de algo, a fim de preencher seu vazio, por meio da síntese das vivências em fluxo na vida. Assim, a consciência é vazia porque é sempre plena de algo diferente dela mesma. Conferir, por exemplo: SARTRE, Jean-Paul. "Uma ideia fundamental da fenomenologia de Husserl: a intencionalidade”. In: Situações I. Tradução de Cristina Prado. São Paulo: Cosac Naify, 2005.

3 A expressão "mundo da vida" (Lebenswelt) foi cunhada por Husserl para se referir ao mundo das vivências pré-teóricas, isto é, ao mundo no qual impera a experiência antepredicativa, no qual os sentidos já aparecem como dados na concretude que caracteriza as vivências cotidianas.

4 Franz Brentano (1838-1917) é considerado um dos grandes responsáveis pelo surgimento da fenomenologia. Entre suas obras, cabe destacar a "Psicologia do ponto de vista empírico", publicada em 1874 . 
sim, o mundo sem a consciência cairia numa total obscuridade. De maneira similar, a consciência sem mundo, para Husserl, tampouco seria possível, pois ela é marcada pela intencionalidade, devendo ser sempre consciência de algo, o que faz com que necessite de um objeto para existir. Como Hannah Arendt afirma,

\begin{abstract}
Husserl afirmou que por meio deste desvio pela consciência e iniciando por uma apreensão completa de todos os conteúdos factuais da consciência (uma nova mathesis universalis) ele seria capaz de reconstruir o mundo que havia se despedaçado. Tal reconstrução do mundo a partir da consciência igualar-se-ia a uma segunda criação, já que nessa reconstrução seu caráter contingente, que é ao mesmo tempo seu caráter de realidade, seria removido, e o mundo não mais apareceria como algo dado ao homem, mas como algo criado por ele (ARENDT, 2002, p. 17).
\end{abstract}

Trata-se da tentativa de Husserl de recriar o mundo desconstruído pelos filósofos da tradição idealista alemã, que, a partir de Kant, conceberam apenas as condições de possibilidade da consciência empírica, sem estabelecer, contudo, uma consciência anterior a ela. O que Husserl faz, então, é estabelecer um estudo acerca da consciência transcendental e da redução fenomenológica, que seria conhecida como $\varepsilon \pi \circ \chi \eta,{ }^{5}$ responsável por suspender todo juízo da consciência fazendo com que o objeto apreendido se mostre em sua mais plena pureza. Assim, a consciência transcendental seria responsável por constituir a consciência empírica, estando, ao mesmo tempo, submetida a ela.

Reformulando as ideias fenomenológicas de Husserl, Sartre questiona a dicotomia entre consciência e mundo pondo em foco a existência de outra consciência, anterior àquela, capaz de pôr como objeto a consciência que tem como objeto o mundo. Trata-se da criação de níveis de consciência, o que responderá ao problema da interdependência entre consciência e mundo posto pela fenomenologia husserliana.

A primeira etapa, conforme a sistematização sartriana, é a consciência de primeiro grau, que pode ser compreendida como consciência originária ou consciência irrefletida. Tal consciência é responsável por pôr e apreender, num mesmo ato, o objeto. A segunda etapa é a da consciência reflexiva, ou consci-

5 Proveniente do grego, o termo $\varepsilon \pi \circ \chi \eta$ (epoché) significa, de modo amplo, "colocar entre parênteses" e "suspensão do juízo", e refere-se à atitude, oposta ao dogmatismo, de neutralidade (suspensão) frente a enunciados, juízos e proposições. 
ência de segundo grau, que ocorre a partir do momento em que a consciência irrefletida, que posiciona o objeto e que toma a si mesma como consciência não posicionada, passa a se posicionar, dividindo-se em consciência reflexionante e consciência reflexionada. Por fim, tem-se a consciência de terceiro grau, também concebida como esfera do "psíquico". Desse modo, Sartre apresenta três níveis de consciência, que estabelecem relações internas e a passagem do eu psíquico para o eu psicofísico.

Os estudos acerca do conhecimento voltam-se para a intencionalidade da consciência, que passa a ser compreendida como um campo transcendental no qual se dá a aparição fenomênica. Tal campo serve de limite para as formulações da fenomenologia e se mostra sempre de forma não categorial, marcado pela agramaticalidade da experiência antepredicativa em si mesma, isto é, pela recepção passiva que constitui o mundo da vida e que antecede toda forma de juízo. ${ }^{6}$ É com base em tais formulações que Sartre chega à noção de intencionalidade como pura atividade agramatical que funda o empírico, uma vez que o transpassa sem se misturar com ele.

É então que se evidenciará a passagem que leva Sartre de sua fenomenologia à concepção de sua moral, tendo por base a noção de que o Ego está fora do âmbito da consciência, uma vez que se encontra lançado no mundo. Não se trata, portanto, de um pólo formal unificador das consciências e das vivências, tampouco um substrato material para as vivências psicológicas, ao contrário do que Husserl propôs por meio da concepção de Ego transcendental.

\section{A consciência irrefletida, o cogito e a consciência refletida}

Conforme explicitamos, Sartre responde à questão posta pela fenomenologia husserliana acerca da dicotomia consciência e mundo sistematizando níveis de consciência, a partir dos quais seria possível conceber a principal tese de sua obra $A$ transcendência do Ego: de que o Ego está situado no mundo.

Para estabelecer a divisão da consciência (ou das consciências) em níveis, Sartre utiliza o cogito cartesiano como ponto de partida. É a partir da afirmação

6 Husserl utiliza a expressão "experiência antepredicativa" para se referir ao caráter receptivo a partir do qual as coisas aparecem na cotidianidade. Só é possível conceber o pré-predicativo a partir da desconstrução do esquema posicionador, originariamente cartesiano, empregado de modo frequente na tradição filosófica, sobretudo, na tradição metafísica. O antepredicativo prescinde da necessidade do campo objetual tal como este é situado no problema do acesso ao mundo exterior e na dicotomia interioridade versus exterioridade, uma vez que parte do pré-dado com vistas às operações das sínteses passivas. 
"Penso, logo existo" (Cogito, ergo sum) que Sartre concebe a existência da consciência de segundo grau, isto é, o cogito representa a constatação de uma consciência que apreende a si mesma enquanto atividade. Em outros termos, com a consciência de primeiro grau, irrefletida, o "si" não era posto no plano do objeto, uma vez que esta é incapaz de refletir acerca de si mesma de forma posicional; com a existência do cogito (uma consciência capaz de colocar a si mesma como objeto posicional) surge a noção de uma consciência anterior à consciência irrefletida, capaz de apreender a si mesma. Além disso, quando tomada como atividade, passa a ser consciência de primeiro grau. Como mostra a citação,

\footnotetext{
como ponto de partida, não pode existir outra verdade senão esta: penso, logo existo; é a verdade absoluta da consciência que apreende a si mesma. Qualquer teoria que considere o homem fora desse momento em que ele se apreende a si mesmo é, de partida, uma teoria que suprime a verdade, pois fora do cogito cartesiano, todos os objetos são apenas prováveis e uma doutrina de probabilidades que não esteja ancorada numa verdade desmorona no nada; para definir o provável, temos que possuir o verdadeiro. Portanto, para que haja uma verdade qualquer, é necessário que haja uma verdade absoluta; e esta é simples e fácil de entender; está ao alcance de todo mundo; consiste no fato de eu me apreender a mim mesmo, sem intermediário (SARTRE, 1987, p. 15).
}

Sartre evidencia o caráter absoluto da verdade existente no cogito cartesiano. Noutros termos, o fato de o indivíduo ser capaz de apreender a si mesmo como consciência que toma a si como objeto é o pressuposto para se compreender seu projeto fenomenológico, o que culminará em sua ontologia fenomenológica, o que será mostrado adiante.

Após formular, sob a influência do cogito cartesiano, a divisão em níveis da consciência, Sartre mostra o que seria esta consciência de primeiro grau, conhecida também como consciência irrefletida: trata-se de uma consciência que tem por atividade ser consciência de um objeto transcendente, sua existência é marcada pelo fato de ser consciência apenas do objeto que se mostra a ela, apreendendo o concreto (em-si), no momento ontológico do modo de aparição. Em outros termos 
Contribuições de uma teoria da consciência irrefletida para uma filosofia da liberdade a partir de A transcendência do Ego
Dnda. Deborah M.

Guimarães [UFSP]

a certeza do cogito é absoluta pois, como diz Husserl, há uma identidade indissolúvel da consciência reflexionante e da consciência refletida (na medida em que a consciência reflexionante não saberia existir sem a consciência refletida). Não resta dúvida que estamos em presença de uma síntese de duas consciências em que uma é consciência da outra (SARTRE, 2010, p. 191).

Dessa forma, a consciência irrefletida conhece a si mesma como interioridade absoluta. Esta, por sua vez, é uma consciência axiomática, irreferencial, prescinde de uma gramaticalidade na medida em que é índice/referência dela mesma. Sendo plena, o "si" da consciência irrefletida está no plano da atividade. Logo, a atividade da consciência irrefletida corresponde ao "eu" da refletida, uma vez que este se dá como um "falso objeto". Contudo, cabe ressaltar que apesar de o Ego ser posto como objeto para a consciência, ele (o ego) não pode ser determinado como um habitante da consciência em questão, na medida em que é dado como uma presença material, pois determina, de fora, o escopo e a estrutura da consciência - o ego transcendental é um ponto fora do fluxo da consciência, necessário para que se dê o modo de aparição.

Percebe-se que Sartre partiu da tese cartesiana do cogito para fundamentar a existência de uma consciência anterior àquela que põe e apreende os objetos dados no mundo. À consciência cuja marca constitutiva é ser consciência de um objeto transcendente Sartre deu o nome de irrefletida. Já à consciência oriunda do posicionamento de si própria enquanto consciência foi denominada de refletida e é esta a responsável por posicionar a consciência do sujeito pensante como um objeto para si própria no cogito. Cabe, agora, pensar essa teoria acerca dos níveis de consciência em relação à conclusão de que o Ego está situado no mundo. Para tal, será necessário, primeiramente, compreender o seguinte trecho:

Husserl é o primeiro a reconhecer que um pensamento sofre uma mudança radical tornando-se reflexivo. Mas cabe necessariamente limitar esta modificação a uma perda de "ingenuidade"? O essencial da mudança não seria a aparição do Eu? É necessário evidentemente recorrer à experiência concreta e ela pode parecer impossível, já que, por definição, uma experiência deste gênero é reflexiva, isto é, provida de um Eu. Para isto basta procurar reconstituir o momento completo em que aparece esta consciência irrefletida (o que é, por definição, sempre possível) (Idem, p. 191-2). 
A grande importância da aparição do Eu à consciência dá-se na medida em que esta passa a ser considerada refletida, ou reflexiva. Para examinar como ocorre a aparição do Eu à consciência, Sartre propõe uma retomada na análise acerca da consciência irrefletida: ocasião em que o Eu ainda não ocupava posição na consciência. Ao procurar reconstituir o momento no qual se constitui a aparição de um dado objeto transcendente, não se faz necessário posicionar a consciência irrefletida como objeto da reflexão, pois, no momento em que tal consciência põe e apreende o objeto, o único foco dessa consciência é o objeto que está sendo apreendido como fenômeno. Para exemplificar tal problemática, Sartre cita o momento em que se está lendo um livro: enquanto o livro está sendo lido, a consciência toma por objeto apenas o livro, seus personagens, sua história; assim, o Eu que estava lendo o livro não habitava essa consciência como objeto, uma vez que esta era apenas consciência do objeto (nesse caso, do livro) e consciência não posicional dela mesma. Noutras palavras, na consciência irrefletida não havia o $\mathrm{Eu}$, do que decorre que, para que o Eu se dê como objeto da consciência, esta deve tomar a si mesma como objeto, como ocorre no cogito cartesiano, no qual a consciência se torna objeto de outra consciência, anterior categoricamente, àquela, que não possui categorias. Porém, cabe ainda questionar como se dá essa apreensão do Eu pela consciência de segundo grau, como ocorre no cogito. Para tal, cabe citar uma passagem de Sartre, na qual ele pergunta: quando uma consciência reflexiva apreende o Eu penso, é dado a ela apreender uma consciência plena e concreta recolhida em um momento real da duração concreta? (Ibidem, p. 194).

Esse questionamento põe em foco o posicionamento de Sartre frente às concepções de um Eu cujo modo de existência se daria como habitante da consciência, e de um Eu como substrato material para as vivências. O Eu não se dá como habitante da consciência na medida em que não ocorre como um momento concreto. Não se trata, portanto, de uma estrutura captada pela consciência durante o modo de aparição: o Eu está além de todas as consciências, ele não aparece para a reflexão como consciência refletida: ele se dá por meio da consciência refletida (Ibidem, p. 195). Logo, o Eu possui uma existência concreta, real, o que faz dele um existente, cujo modo de ser é transcendente. Todavia, cabe salientar que o $E u$ só aparece a partir do ato reflexivo, como uma espécie de elemento decorativo, que só se mostra quando nada realiza - o Eu constitui o objeto transcendente do ato reflexivo, enquanto que nos atos irrefletidos o que ocorre é uma reflexão sem o $E u$.

Com a distinção entre dois tipos de consciência capazes de realizar ações diversas, cabe agora examinar uma questão que diz respeito à estrutura dos atos reflexivos, assim como também à dos atos irrefletidos. Sabe-se que a estrutura 
de ação da consciência refletida é tomar a consciência como objeto, posicionando-a. Já a consciência irrefletida tem por estrutura a apreensão de um objeto transcendente que ela mesma põe, isto é, a consciência irrefletida volta-se apenas para o objeto que está sendo apreendido no momento do modo de aparição.

Para descrever tal atividade, Sartre cita n'A transcendência do Ego o exemplo da consciência que apreende Pedro precisando de socorro. Para a consciência o único objeto existente naquele momento é "Pedro-que-deve-ser-socorrido", em outros termos, a consciência volta-se apenas para a necessidade de socorrer Pedro sem se posicionar a si mesma como objeto. Assim, o fato de Pedro precisar de socorro impulsiona a consciência como uma espécie de força motriz, levando-a à ação de socorrer Pedro. Conclui-se, portanto, o que já havia sido formulado anteriormente: não há um $E u$ na consciência irrefletida, pois se trata de uma consciência impessoal. Como afirma Franklin Leopoldo e Silva,

não há, pois, Eu no plano da consciência irrefletida: há o apelo dos objetos, estou no mundo dos objetos e são eles que constituem a unidade que posso encontrar na consciência que deles tenho. Não se trata de uma desatenção momentânea do Eu para consigo mesmo, trata-se da estrutura da consciência (SILVA, 2004, p. 41).

Percebe-se que a consciência irrefletida não necessita posicionar-se a si mesma como objeto para existir, ela é autorreferencial, é índice de si mesma. Para existir, tal consciência não precisa de uma reflexão, basta a existência de um objeto para preencher seu vazio constitutivo. Assim, a consciência é vazia porque é sempre plena de algo que não é ela mesma; é preenchida por um objeto transcendente que a requisita para a obtenção de sentido. É desse modo que a consciência irrefletida assinala uma prioridade ontológica sobre a consciência refletida, uma vez que esta só pode existir a partir de uma reflexão, o que depende da consciência de segundo grau. Nas palavras de Sartre:

sem dúvida, pode-se conceber que uma consciência apareça imediatamente como refletida, em certos casos. Mas assim mesmo, então, o irrefletido tem prioridade ontológica sobre o refletido uma vez que ele não tem nenhuma necessidade de ser refletido para existir e que a reflexão supõe a intervenção de uma consciência de segundo grau (SARTRE, 2010, p. 199). 
A consciência irrefletida diferencia-se, dessa forma, da refletida pelo fato de ser autônoma e impessoal. Além disso, a qualidade do desejo irrefletido é de se transcender à medida que apreende no objeto a qualidade desejável (Idem, p. 199). É no plano irrefletido que ocorrem as ações altruístas, por exemplo: eu socorro Pedro porque ele deve ser socorrido, está diante de mim como um objeto que necessita de socorro, para que minha consciência tome este fato como objeto e me leve a socorrer Pedro não é necessária nenhuma reflexão, basta a apreensão do "adiante-para-ser-socorrido", como coloca Sartre.

É com base em tais conclusões acerca das concepções de consciência refletida e consciência irrefletida que surge a necessidade de se pensar o projeto ético sartriano. A consciência irrefletida está diretamente ligada a um projeto altruístico na medida em que dispõe o ser humano ante a um dever, ao qual é impulsionado antes mesmo que ocorra o plano da reflexão. Tomando como base tais afirmações, cabe agora questionar: em que ponto e de que forma a teoria acerca da existência de níveis de consciência formulada por Sartre contribui para uma filosofia voltada à liberdade do indivíduo e à sua moral? Como, ainda, relacionar a teoria de uma consciência irrefletida com a conclusão obtida por Sartre de que o Ego estaria no mundo, e não, como se supunha, na consciência? Para tal, cabe examinar, primeiramente, a natureza e a constituição do Ego, pois ao traçar as estruturas correspondentes às consciências refletidas e irrefletidas, ficou demonstrado o fato de o Eu ser passível de ser captado apenas pela consciência reflexiva, sendo, portanto, existente e transcendente; sua realidade é similar à realidade dos objetos, apesar de serem diferentes, o que fica claro a partir do seguinte trecho:

o Eu é exterior à consciência espontânea e captado apenas sempre pela consciência reflexiva. Não é originário. O que pode ser dito também em outras palavras: o Eu é um existente e sua realidade transcende a consciência, tal como a realidade dos objetos, dos quais ele evidentemente se diferencia (SILVA, 2004, p. 41).

\section{Natureza e constituição do Ego e consciência de terceiro grau}

Após traçar as diferenças existentes entre o plano refletido e o irrefletido, cabe agora questionar o modo de aparição do Ego, bem como sua natureza e sua constituição. Como foi suscitado no fim do tópico anterior, o Ego é caracte- 
rizado por ser captável apenas pela consciência reflexiva, ou de segundo grau; ele possui existência real e transcende a consciência. Como, então, Sartre chega a tais conclusões?

N'A transcendência do Ego, Sartre questiona como se dá sua presença na consciência, isto é, se se trata de um princípio de unificação ou de uma presença real, estando ambos relacionados à suposição do Ego como habitante da consciência. Assim, o Ego, que é a junção do Eu e do Mim (je + moi), é considerado um objeto, pois transcende à consciência durante sua apreensão. Por ser objeto, o Ego possui uma aparência passiva, na medida em que além de ser apreendido ele também é constituído pela consciência reflexiva. É no objeto Ego que a consciência projeta sua própria espontaneidade. Contudo, o Ego também possui um aspecto ativo, pois produz os estados existentes nele. Ao ser produtor dos estados e também passivo, o Ego é capaz de sofrer um contrachoque oriundo dos estados por ele criados, transformando-se numa síntese de passividade e atividade.

Além de produzir seus estados, é Ego também é responsável por sustentar suas qualidades, produzindo uma espontaneidade conservadora. Trata-se de uma espontaneidade de certa forma "encantada" (SARTRE, 2010, p. 212) que, mesmo possuindo um aspecto racional, guarda ainda um fundo de inteligibilidade, uma espécie de "procissão mágica" que culmina na seguinte conclusão: a espontaneidade do Ego escapa de si mesmo, sendo este sempre ultrapassado por aquilo que produz, ainda que o Ego e sua produção sejam o mesmo. ${ }^{7}$ Como Sartre afirma,

a ligação que ele põe é perfeitamente irracional porque o produtor é passivo em relação à coisa criada. (...) $\mathrm{E}$ nós compreendemos o sentido disso: o Ego é um objeto apreendido mas também constituído pela consciência reflexiva. É um lar virtual de unidade, e a consciência o constitui em sentido inverso àquele que segue sua produção real: o que é realmente primeiro são as consciências, por meio das quais se constituem os estados, depois, mediante os estados, o Ego. Mas como a ordem é invertida por uma consciência que se aprisiona no Mundo para escapar de si, as consciências são dadas como emanando dos estados e os estados como produ-

7 Cf.: "Seria interessante estudar os diversos tipos de procissões do Ego a seus estados. Trata-se, na maior parte do tempo, de uma procissão mágica. Algumas vezes ela pode ser racional (no caso da vontade refletida, por exemplo). Mas sempre com um fundo de ininteligibilidade cuja razão apresentaremos adiante" (SARTRE, 2010, p. 212). 
Contribuições de uma teoria da consciência irrefletida para uma filosofia da liberdade a partir de A transcendência do Ego
Dnda. Deborah M.

Guimarães [UFSP]

zidos pelo Ego. Segue-se que a consciência projeta sua própria espontaneidade no objeto Ego para lhe conferir o poder criador que lhe é absolutamente necessário (SARTRE, 2010, p. 213).

A passagem supracitada assinala diversos aspectos importantes acerca da constituição do Ego, a saber: a irracionalidade existente na relação entre produtor e produção, uma vez que o produtor é passivo, e não ativo como deveria ocorrer no processo de criação; o fato de o Ego ser responsável por unificar e, ao mesmo tempo, produzir, os estados e ações; e, por fim, de ser considerado o objeto no qual a consciência projeta sua espontaneidade, conferindo-lhe, "magicamente", seu poder criador. Assim, a capacidade de uma passividade criar outra passividade de maneira espontânea, como ocorre no Ego, tem como fundo a permanência de uma lembrança da espontaneidade da consciência, responsável por transferir ao objeto o poder criador. ${ }^{8}$ A consciência confere tal capacidade ao objeto, neste caso ao Ego, porque está aprisionada no Mundo em um movimento de fuga de si mesma, uma vez que o "si" da consciência aparece como o objeto que se põe na aparição. É por esses motivos que o Ego é passível de ser afetado e a consciência não: nada age sobre a consciência porque ela é a causa de si mesma. Já em relação ao Ego, além de sofrer o contrachoque citado anteriormente, os estados e ações voltam-se sobre Ele a fim de qualificá-lo.

A relação Ego-consciência é marcada por dois fatores: intimidade e indistinção. Intimidade na medida em que o Ego ocorre como se fosse íntimo à consciência, dela se diferindo apenas por sua opacidade, que será a marca constitutiva da indistinção, ou seja, de uma interioridade vista de fora ou, em outros termos, de uma projeção degradada da interioridade. Dessa forma, trata-se de uma intimidade/interioridade que é exterior àquilo a que se refere, o que faz do Ego também uma síntese de interioridade e transcendência: para conhecer-se é necessário tomar para si o ponto de vista do outro. ${ }^{9}$

A irracionalidade presente nas relações das quais o Ego faz parte, juntamente à ligação "mágica" pela qual se dá a espontaneidade desta consciência, cor-

8 Cf.: "Ocorre que esta espontaneidade, representada e hipostasiada em um objeto, torna-se uma espontaneidade bastarda e degradada, que conserva magicamente seu poder criador na exata medida em que se torna passiva" (SARTRE, 2010, p. 213).

9 Há uma característica fortemente empática no processo de síntese entre interioridade e transcendência que nos remete a possíveis influências de Dilthey à obra de Sartre. Dilthey (2010) define compreensão como um "reconhecimento do eu no tu", isto é, ele busca resolveu o problema do acesso ao mundo exterior por meio de um processo no qual a intersubjetividade é assegurada pela verificação da interioridade na exterioridade, compreendendo a objetividade como outras subjetividades possíveis. 
respondem àquilo que será denominado consciência de terceiro grau, na qual impera o domínio do psíquico. Tal domínio é considerado não-fenomenológico, uma vez que seu objeto é o corpo e este possui um caráter mistificador. Assim, o instrumento para investigação do campo psíquico será aquilo que Sartre denomina reflexão impura, que ocorre na medida em que um vivido imediato existente no campo irrefletido passa a situar-se no campo psíquico, isto é, tal reflexão engloba o vivido imediato no campo psíquico. Como exemplo, cabe citar a relação entre o ódio e a repulsa exposta por Sartre: sendo o ódio um estado, este se dá como intermediário entre o corpo e o vivido, assim, a relação do ódio ao vivido particular de repulsa não se dá logicamente, mas por meio de uma ligação "mágica", uma vez que a repulsa surge à reflexão como uma emanação espontânea do estado, neste caso, do ódio. São tais relações que marcam a irracionalidade presente na esfera do psíquico. Sua atividade difere-se da reflexão pura, pois não rastreia o momento originário em que uma aparição se manifesta como sentido. Em outros termos, no psíquico não se questiona como se dá a emergência do sentido, isto é, o momento originário da vivência.

Sendo o Ego uma unidade transcendente de estados e ações, surge a necessidade de se conceber um intermediário entre eles: a qualidade. Esta se caracteriza como uma disposição psíquica e, enquanto tal, como um objeto transcendente, que representa o substrato dos estados como os estados representam o substrato dos vividos (Erlebnissen $)^{10}$ (Idem, p. 206). Cabe explicitar as diferenças essenciais entre a qualidade e o estado, a saber, o estado é unidade noemática ${ }^{11}$ de espontaneidades, a qualidade é unidade de passividades objetivas (Ibidem, p. 207). Ou seja, quando não se tem a consciência do ódio, este ocorre como existente em ato.

O motivo de unir em um só tópico a consciência de terceiro grau e a natureza do Ego consiste no fato de este aparecer à reflexão como um objeto que realiza uma síntese permanente do psíquico, estando, ao mesmo tempo, ao lado dele, pois se trata de um Ego psíquico - não psicofísico. O Ego é transcendente aos estados que unifica, tornando-se uma totalidade infinita de estados e ações.

10 Devido à forte influência da recepção francesa da fenomenologia, diversas vezes nos deparamos com traduções que buscam elucidar a fenomenologia como ciência dos vividos, uma vez que o vocábulo Erlebnis aparece traduzido em francês pelo termo vécu. Conforme nossa compreensão, em alemão, a palavra Erlebnis não contém o caráter participial passado que a tradução francesa sugere. Erlebnis deriva da composição entre o verbo erleben (vivenciar) e o sufixo -nis (geralmente usado para criar substantivos a partir de verbos e adjetivos), que denota um caráter produtivo, isto é, resultante. Nesse sentido, a vivência seria o resultado da ação vivenciar, que, sendo em fluxo, possui um sentido simultaneamente passado e presente.

11 Cabe citar que o termo noema refere-se à dicotomia noesis-noema proposta por Husserl. Noesis refere-se ao ato de perceber; enquanto que noema ao objeto da percepção. O noema é a coisa-em-si, como fenômeno da consciência. 
Logo, o Ego está para os objetos psíquicos assim como o Mundo está para as coisas (Ibidem, p. 209). Por estar situado junto ao psíquico, o Ego aparece como um objeto de natureza duvidosa, ele só aparece quando não é olhado, em outros termos, o Ego só aparece no horizonte, atrás do estado, quando o olhar reflexivo se fixa sobre a vivência. Quando se pretende alcançá-lo sem atravessar a vivência e o estado, diretamente, voltando-se para ele, o Ego se esvai. Nas palavras de Sartre: procurando apreender o Ego por ele mesmo e como objeto direto de minha consciência, eu caio sobre o plano irrefletido e o Ego desaparece com o ato reflexivo (Ibidem, p. 218). A partir daí, percebe-se que o Ego possui uma natureza fugidia, e que, quando fixado em si mesmo, passa do plano refletido ao irrefletido, degradando-se mediante a perda de sua intimidade com a consciência.

No plano refletido, isto é, na consciência refletida, o Ego atua realizando uma síntese de imanência e interioridade. Já por meio da intuição o Ego sintetiza transcendência e intimidade, e, no psíquico, unifica os estados e ações tendo como agente intermediário a qualidade. Ao cair para o plano irrefletido, com a consciência de primeiro grau, o Eu-conceito passa a se constituir de um vazio transcendente, marcado pela perda da intimidade. Assim, o corpo passa a ser considerado um preenchimento ilusório deste Eu, situando-se no domínio do psicofísico.

Com a passagem para o eu psicofísico e o retorno à consciência irrefletida, após estruturar a constituição do Ego, cabe agora examinar em que sentido o ato de pôr e apreender o objeto da consciência irrefletida está relacionado ao engajamento proposto por Sartre em seu projeto ético. Tais assuntos serão brevemente abordados no tópico seguinte desse estudo, que apresentará as possíveis conclusões acerca dos assuntos já abordados.

\section{Como a teoria da consciência irrefletida contribui para uma filosofia da liberdade}

Resumidamente, Sartre partiu da fenomenologia de Husserl para elaborar o seu projeto fenomenológico: assimilou a noção de intencionalidade visando estabelecer a maneira pela qual se daria o modo de aparição, a apreensão da realidade, e o problema concernente à dicotomia consciência e mundo, visando, por fim, alcançar um propósito ético.

Da noção de intencionalidade surgiu a necessidade de repensar o cogito cartesiano, aplicando-lhe o método fenomenológico. Assim, chegamos a duas conclusões: primeiro, a consciência é vazia porque está sempre preenchida de 
algo que não é ela mesma, ou seja, de um objeto transcendente que necessita da consciência para obter sentido, tal consciência, responsável por pôr e apreender num mesmo ato o objeto, foi denominada consciência irrefletida, ou de primeiro grau; segundo, a consciência responsável por apreender a consciência do "Eu penso" no cogito cartesiano foi denominada consciência reflexiva, ou consciência de segundo grau. A diferença crucial entre ambas é o fato de que a consciência irrefletida é consciência não-posicional de si mesma, enquanto que a reflexiva posiciona o "si" de si mesma como objeto.

Dos dois níveis de consciência já mencionados Sartre parte para a elaboração de um terceiro nível, denominado consciência de terceiro grau, ou, em outros termos, psíquico, região marcada pela irracionalidade e pela presença de ligações peculiares nas relações entre o Ego e seus estados, qualidades e ações, na medida em que o Ego os unifica juntamente às vivências. Com o estudo do domínio do psíquico, chega-se à conclusão de que o Ego só pode ser apreendido por meio da consciência irrefletida, isto é, no momento em que a consciência apenas se volta ao objeto, sem fixá-lo diretamente.

Se o Ego só pode ser apreendido em si mesmo pela consciência irrefletida, conclui-se que sua existência é situada no Mundo, uma vez que compartilha com os demais objetos a "objetualidade" e a realidade que o caracterizam também como um objeto transcendente. Em outros termos, o Ego não é um habitante da consciência como se supunha até então, mas um objeto que está lançado no mundo, em meio à contingência, à espera de uma consciência que lhe conferirá sentido no instante em que o apreender. Dessa forma,

ser é explodir para dentro do mundo, é partir de um nada de mundo e de consciência para subitamente explodir-como-consciência-no-mundo. Se a consciência tentar se reconstituir, coincidir enfim consigo mesma, então imediatamente, a portas fechadas, se aniquilará (SARTRE, 2005, p. 55).

Outro ponto importante que corrobora a elaboração do projeto ético sartriano no esteio da fenomenologia é a concepção de exterioridade do Eu: a afirmação de que o Eu é sempre lançado para fora, no mundo. Como consequência de tal afirmação surge a conclusão de que o conhecimento de si próprio advém apenas do ponto de vista alheio. Se se concebe, então, que o Eu é exterior, o indivíduo deixa de ter certeza de seu próprio Eu, isto é, gera-se uma insegurança perante o 
fato de meu Eu ser exterior como os dos outros indivíduos. Sendo o Ego um ser no Mundo, nossa existência é projetada para um agir-no-mundo, uma vez que a consciência precisa de tal Mundo para existir, preencher-se, completar-se; e o Mundo precisa da consciência para obter sentido.

À noção de Ego como ser-no-mundo une-se também a concepção de espontaneidade da consciência como algo originário, em detalhes: na medida em que a espontaneidade da consciência desvela o fato de esta não poder ser de outro modo que não o de si própria, a consciência aprisiona a si mesma em sua própria lucidez, fazendo com que o indivíduo seja "obrigado" a ser livre, pois é pleno de uma consciência lúcida acerca de si mesma como projeção de um Ego que está situado em um Mundo, daí resulta o fato de o Ego ter-que-ser um ser-no-mundo. A consciência projeta-se no Ego e, por consequência, no Mundo, a fim de escapar de si mesma, desse estado pleno de lucidez e espontaneidade que a remete a uma constante angústia oriunda da contingência que perpassa o indivíduo frente à liberdade que lhe aparece como uma fatalidade causada por sua própria consciência. Como afirma Franklin Leopoldo e Silva,

sendo o Eu exterior, não estou mais seguro do meu próprio Eu do que da egoidade dos outros, pois o meu Ego é um ser no mundo, assim como o de todos os outros. Mas, seguramente porque a espontaneidade da consciência aparece como originária, isto é, a liberdade aparece como se fosse uma fatalidade, algo de que não podemos escapar, a consciência constitui o Ego e nele se projeta como para escapar de si mesma, da própria espontaneidade que, por não se reportar a nenhum solo fundador, é angustiante pelo que apresenta de instável e movediça (SILVA, 2004, p. 45).

Dessa forma, o fato de a consciência ter que ser como é e não poder ser de outro modo assinala que esta tem a si mesma como base, ou seja, só pode encontrar sentido para sua existência em si própria e não nas coisas alheias, pois nesse caso ela estaria fugindo de sua espontaneidade, aprisionando-se, negligenciando a liberdade que lhe é própria e constitutiva: a liberdade não é, com efeito, uma qualidade da consciência, ela é a própria existência, anterior a toda definição ou determinação (DARTIGUES, 2005, p. 88-9).

Porém, cabe ressaltar que essa liberdade constitutiva da existência só é possível quando inserida no mundo, isto é, é necessário que haja um mundo para que se dê a existência, e assim, a liberdade. Estando o Ego lançado no mundo e sendo esse mesmo Ego responsável por se projetar na consciência, o mundo 
é indiretamente também projetado na consciência; e vale ressaltar: não apenas projetado, como também posto e apreendido pela consciência, na medida em que o Mundo se constitui como correlato da consciência e tem como fio condutor para tal correlação o Ego. Como correlato do Mundo, a consciência é responsável por desvelar a contingência do indivíduo compreendido como ser-no-mundo ${ }^{12}$; a consciência traz ao mundo as possibilidades oriundas do caráter de pura possibilidade do Eu, característico da liberdade que lhe é imposta.

Com a concepção de que o indivíduo é constituído de algo que lhe é exterior, findou-se, então, o dualismo que costumava opor interioridade e exterioridade, como se o exterior não pudesse proporcionar conhecimento da interioridade. Noutras palavras, com o Ego lançado no mundo, o indivíduo, a fim de se conhecer, passou a ter a necessidade de trazer para si o ponto de vista do outro, projetando suas ações com base neste mundo ao qual está inserido. Assim, foi a representação do Ego o fator responsável por trazer as questões éticas ao discurso fenomenológico proposto por Sartre.

A ontologia fenomenológica sartriana foi concebida como meio de responder à dicotomia problematizada por Husserl entre transcendental e empírico, uma vez que para Sartre ambos se uniam para formar aquilo que seria denominado concretude. Com tais afirmações, o ser também passou a ser concebido como aquilo que se dava no modo de aparição, fazendo com que a fenomenologia fosse compreendida e utilizada como um método, e não como uma ciência de rigor tal como propunha Husserl. Foi assim que o ser passou a ser posto pela consciência por meio de sua intencionalidade, daí a frase que serve de título à obra A transcendência do Ego: a afirmação de que o Ego é um objeto transcendente que é posto e apreendido, num mesmo ato, pela consciência irrefletida, que se situa no mundo como pura atividade.

\section{Considerações finais}

Procuramos mostrar como a divisão da consciência em níveis corroborou para a elaboração de um projeto ético cujo fator principal é a liberdade. Assim, a consciência irrefletida, como consciência não posicional dela mesma, apenas põe e apreende os objetos transcendentes. Nesse ato realizado pela consciência

12 Podemos conceber essa concepção de ser-no-mundo como contingente como uma marca da forte influência da analítica existencial de Heidegger. Em Ser e tempo, texto publicado em 1927, Heidegger sistematiza sua hermenêutica da facticidade a partir de um fenômeno estrutural: ser-no-mundo, cuja indeterminação ontológica originária aparecerá a partir da capacidade de se assumir possibilidades de ser abertas pela compreensão na facticidade. 
por meio de sua intencionalidade, visa-se apenas o objeto que está sendo posto e apreendido. É então que o Eu aparece: no plano irrefletido.

A consciência irrefletida apreende o Eu porque a existência humana pressupõe a sua própria inserção no mundo, isto porque o Ego está no mundo e não na consciência como se costumava supor. Percebe-se, então, que o Eu aparece no plano irrefletido porque a consciência irrefletida, enquanto objeto da consciência de segundo grau, está no mundo como pura atividade.

Se o indivíduo deve ser compreendido como ser-no-mundo porque este é o objeto da consciência irrefletida, o Ego só pode estar lançado no mundo e, portanto, sujeito à espontaneidade da consciência que projeta no indivíduo uma liberdade que deve ser necessariamente assumida, como uma espécie de imperativo ético. Em outros termos, o indivíduo está fadado a ser livre porque a consciência se autoprojeta no mundo, gerando o fator determinante da liberdade e constitutivo da contingência: a possibilidade.

Logo, tendo o mundo como objeto, a consciência percebe o que Sartre denomina de fatalidade da espontaneidade e passa a se angustiar na medida em que assume o fato de seu Eu ser apenas um objeto transcendente que participa das possibilidades do mundo que the aparecem como alternativas, opções que ele deve escolher porque é livre. ${ }^{13}$ Seu Eu não é, portanto, mais certo que os demais, o que obriga a consciência irrefletida a determinar-se, instantaneamente, como uma existência impessoal.

13 Podemos citar a "escolha" como uma das divergências entre os sistemas de Heidegger e de Sartre. Em ambos os autores podemos identificar um projeto de fenomenologia da liberdade, isto é, de desobstrução de preconceitos sedimentados a partir da concepção de que não há uma necessidade, ou uma causalidade, que determine o campo das vivências humanas. Contudo, a assunção de possibilidades, em Heidegger, não se dá de modo aleatório uma vez que tais possibilidades se originam do mundo fáctico em questão - como numa espécie de possível conciliação entre a causalidade e a contingência embasadas na indeterminação ontológica originária. Portanto, não cabe falar em escolha, na analítica existencial, porque não há um ato de vontade que se estabeleça anteriormente à existência: o que ocorre é, de modo simultâneo, abertura de campos de sentido e atualização/mobilização de possibilidades de ser decorrentes dessa abertura. 
ARENDT, Hannah. "O que é a filosofia da Existenz?" In: A dignidade da politica: ensaios e conferências. Tradução de Helena Martins e outros. Rio de Janeiro: Relume-Dumará, 1993.

DARTIGUES, André. O que é a fenomenologia? Tradução de Maria José J. G. de Almeida. São Paulo: Centauro, 2005.

DILTHEY, Wilhelm. A construção do mundo histórico nas ciências humanas. Trad. Marco Antonio Casanova. São Paulo: Editora UNESP, 2010.

HEIDEGGER, Martin. Sein und Zeit. Neunzehnte Auflage. Tübingen: Max Niemeyer Verlag, 2006.

HUSSERL, Edmund. Ideias para uma fenomenologia pura e para uma filosofia fenomenológica: introdução geral à fenomenologia pura. Tradução de Márcio Suzuki. Aparecida, SP: Ideias \& Letras, 2006.

. Meditações cartesianas: introdução à fenomenologia. Tradução de Maria Gorete Lopes e Sousa. Porto, Portugal: Rés Editora, 19??.

. Die Krisis der europäischen Wissenschaften und die transzendentale Phänomenologie. Hamburg: Felix Meiner Verlag, 2012.

MOURA, Carlos Alberto Ribeiro de. "Prefácio". In: HUSSERL, Edmund. Ideias para uma fenomenologia pura e para uma filosofia fenomenológica: introdução geral à fenomenologia pura. Tradução de Márcio Suzuki. Aparecida, SP: Ideias e Letras, 2006. (Coleção Subjetividade Contemporânea).

SARTRE, Jean-Paul. "A transcendência do Ego esboço de uma descrição fenomenológica". In: Cadernos Espinosanos / Estudos sobre o século XVII. Vol. XXII. Tradução de Alexandre de Oliveira Torres Carrasco. São Paulo: Departamento de Filosofia da FFLCH-USP, 2010.
.O Existencialismo é um Humanismo. In: Coleção Os Pensadores. 3. ed. Tradução de Rita Correia Guedes. São Paulo: Nova Cultural, 1987.

. "Uma ideia fundamental da fenomenologia de Husserl: a intencionalidade". In: Situações I. Tradução de Cristina Prado. São Paulo: Cosac Naify, 2005.

SILVA, Franklin Leopoldo e. Ética e literatura em Sartre: ensaios introdutórios. São Paulo: Editora UNESP, 2004. (Coleção Biblioteca de Filosofia)

ZAHAVI, Dan. A fenomenologia de Husserl. Tradução de Marco Antonio Casanova. Rio de Janeiro: Via Verita, 2015. 